\title{
Probiotics may not prevent the deterioration of necrotizing enterocolitis from stage I to II/III
}

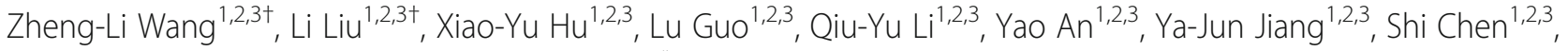
Xue-Qiu Wang ${ }^{1,2,3}$, Yu He $\mathrm{H}^{1,2,3}$ and Lu-Quan Li $\mathrm{i}^{1,2,3^{*}}$

\begin{abstract}
Background: Probiotic therapy can reduce the incidence of NEC. Therapeutic use of probiotics after NEC diagnosis reduces the severity of NEC in preterm infants or full-term infants is unclear. To evaluate the effect of probiotics on preventing the deterioration of necrotizing enterocolitis (NEC) from stage I to II/III.

Methods: A retrospective matched cohort study was performed. Included patients were ultimately divided into two groups: the probiotic treatment group (probiotics were used $\geq 4$ days) and the no probiotic treatment group. The differences in deterioration trends between the two groups were compared. Additionally, the risk factors associated with the deterioration of NEC were further analyzed with a case-control study.

Results: A total of 231 infants met the inclusion criteria. Eighty-one pairs were matched according to similar gestational age and birth weight. Before matching, we found that the rate of deterioration of NEC from stage I to II/II in the group with probiotic treatment was similar to that in the group without probiotic treatment (23.1\% [25/ 108] vs $26.0 \%$ [32/123], $P=0.614$ ). After matching, the rate of deterioration of NEC between the two groups still had no significant difference (21.0\% [17/81] vs $27.2 \%$ [22/81], $P=0.358)$. Logistic regression analysis showed that sepsis after NEC was an independent risk factor for NEC deteriorating from stage I to II/III (OR 2.378, 95\% Cl 1.005-5.628, $P=0.049$ ).
\end{abstract}

Conclusion: Probiotics may not prevent the deterioration of NEC from stage I to II/III in infants, but this conclusion should be treated with caution.

Keywords: Intestinal diseases, Microbiota, Matched case-control study

\section{Background}

Necrotizing enterocolitis (NEC) is a serious gastrointestinal disease with a mortality rate reaching up to 20 $30 \%[1,2]$, and it has become an important cause of neonatal death. There have been no targeted treatment protocols for NEC, and we generally use symptomatic treatment. Infants with NEC commonly receive cessation of enteral nutrition, broad-spectrum antibiotics,

\footnotetext{
* Correspondence: liluquan123@163.com

Zheng-Li Wang and Li Liu made equal contributions to this work. 'Department of Neonatal Diagnosis and Treatment Center, Children's Hospital of Chongqing Medical University, No 136, Zhong shan 2 Road, Yuzhong district, Chongqing 400014, People's Republic of China

${ }^{2}$ Key Laboratory of Pediatrics in Chongqing, Chongqing 400014, People's Republic of China

Full list of author information is available at the end of the article
}

gastrointestinal decompression and supportive treatment if necessary. Studies have suggested that prophylactic probiotic therapy can reduce the incidence of NEC in preterm infants [3-5]' and meta-analyses have confirmed these findings [6, 7]. Studies of probiotic effects in term infants have focused on allergic diseases, immunomodulation, infectious and antibiotic-associated diarrhea, sepsis or growth [8]. Furthermore, approximately $10 \%$ of NEC cases occurred in full-term infants, but few studies have focused on this group of infants [9]. Compared with infants with stage I NEC, infants with stage II/III NEC, especially infants with stage III NEC, incur higher costs for hospitalization and care and have poorer prognoses [10]. However, until now, whether the therapeutic use of probiotics after NEC diagnosis reduces the

(c) The Author(s). 2019 Open Access This article is distributed under the terms of the Creative Commons Attribution 4.0 International License (http://creativecommons.org/licenses/by/4.0/), which permits unrestricted use, distribution, and reproduction in any medium, provided you give appropriate credit to the original author(s) and the source, provide a link to the Creative Commons license, and indicate if changes were made. The Creative Commons Public Domain Dedication waiver (http://creativecommons.org/publicdomain/zero/1.0/) applies to the data made available in this article, unless otherwise stated. 
severity of NEC in preterm infants or full-term infants is unclear. The aim of this study was to evaluate the effect of probiotic therapy on preventing the deterioration of NEC from stage I to stage II/III in infants.

\section{Methods}

\section{Setting}

The Department of Neonatology, Children's Hospital of Chongqing Medical University, Chongqing, China, is a national clinical specialty department that currently has 300 beds and admits approximately 10,000 newborns each year.

\section{Data collection}

A retrospective cohort study was conducted. Medical records were reviewed for all infants with stage I NEC who were admitted to the Children's Hospital of Chongqing Medical University from January 2012 to March 2016. The clinical stage of NEC was defined according to the criteria that was originally proposed by Bell et al. [11] and the modified criteria subsequently reported by Walsh and Kriegman [12]. Stage I NEC was defined according to the presence of clinical signs such as temperature instability, gastric residuals, emesis, abdominal distension, occult blood in the stool (without fissure); further confirmation came through radiographic or sonographic findings of dilated intestinal tract with slight intestinal obstruction or normal intestine. Stage II NEC was defined according to the presence of clinical signs such as gross blood in the stool (without fissure), slight metabolic acidosis along with the clinical signs of stage I NEC and having radiographic or sonographic findings of pneumatosis intestinalis or portal vein gas. The criteria of stage III NEC included nonspecific clinical features such as hypotension, bradycardia and apnea in addition to the clinical features of stage II NEC and radiographic or sonographic findings of ascites or pneumoperitoneum.

The age of NEC onset was defined as the day when one of the following signs or symptoms appeared: gastric residuals, emesis, abdominal distension, bloody stool (without fissure), diarrhea, or hypoactive bowel sounds. Patients with stage $\geq$ II NEC at admission or with intestinal malformation (intestinal malrotation, intestinal stricture, intestinal atresia, Hirschsprung disease, anal atresia) or patients whose duration of hospitalization was $\leq 3$ days were excluded from the study. Patients who received probiotics for $\leq 3$ days were also excluded from further study (Fig. 1).

\section{Probiotic and other treatments}

When stage I NEC was diagnosed, all patients included in this study received similar treatment protocols including cessation of enteral nutrition, total parental nutrition support, broad-spectrum antibiotic therapy and gastrointestinal decompression. For infants whose conditions deteriorated to stage II/III NEC, intensive care, including cardiorespiratory support and blood or blood product transfusion, was also provided when necessary.

Continuous clinical evaluation for infants and abdominal X-ray, full blood test (including white blood cells, platelet counts, immature/total neutrophils, etc.), $\mathrm{C}$-reactive protein and procalcitonin examination were performed. If infants' clinical conditions improved $72 \mathrm{~h}$

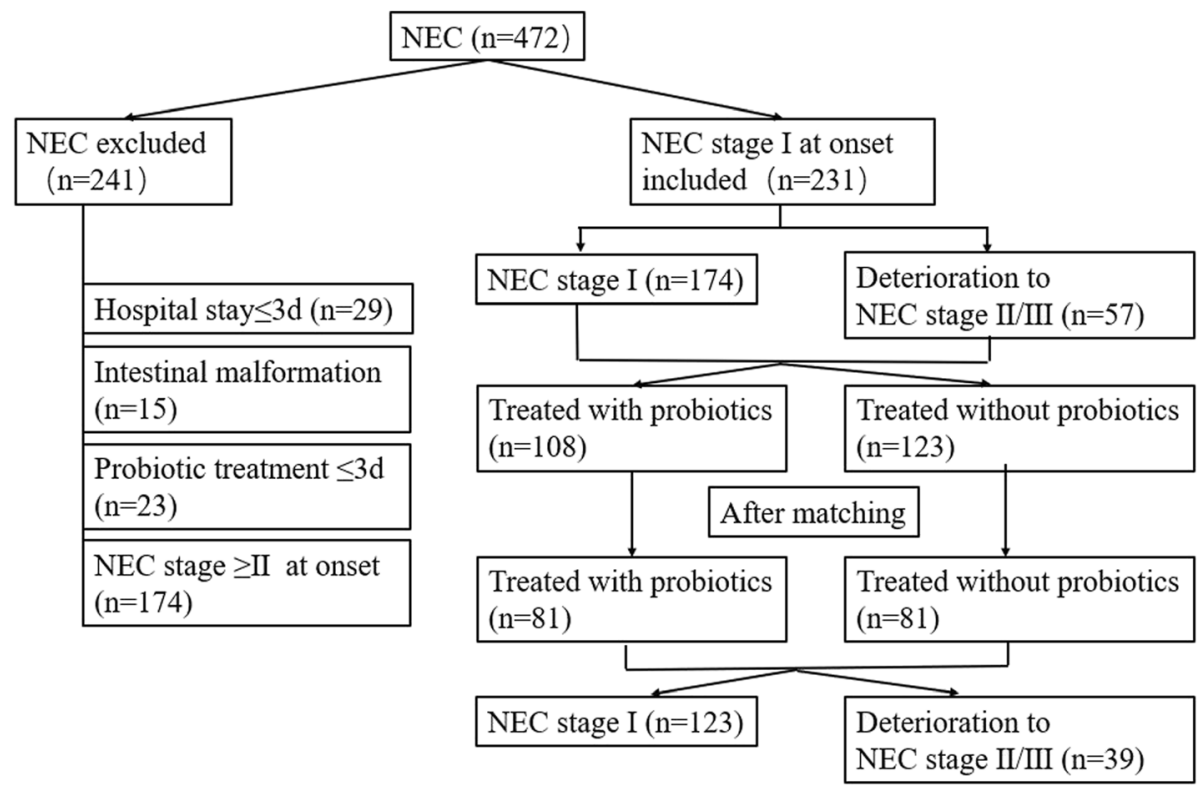

Fig. 1 Flow chart for the study population and the subgroups 
after diagnosis of NEC Bell stage I, enteral feeding was initiated (starting with $10 \mathrm{ml} / \mathrm{kg}$ of body weight formula milk, and then adding $10-20 \mathrm{ml} / \mathrm{kg}$ of body weight per day). When the patients were permitted to be fed, the infants in the probiotic group were treated with probiotics ( $\geq 4$ days, one tablet at a time, bid), and the other infants in the control group were not treated with probiotics. The probiotics used in this study were Bifidobacterium tetravaccine tablets (live) [trade name: Hangzhou Longda Xinke Biological Pharmaceutical Co., Ltd., $0.5 \mathrm{~g} /$ tablet] with no less than $0.5 \times 10^{6}$ colonyforming units (cfu) infant Bifidobacteria, Lactobacillus acidophilus and Enterococcus faecalis, $0.5 \times 10^{5} \mathrm{cfu}$ Bacillus cereus. The antenatal information, basic information, complications and treatment protocols of all patients included in this study were reviewed and compared between the two groups.

\section{Pairing method}

To avoid attributing probiotics as the cause of advanced NEC stage when it may actually be attributable to gestational age and birth weight, a matched design was employed in our study. We performed 1:1 matching according to close gestational age (difference was $\leq 3$ days) and birth weight (difference was $\leq 400 \mathrm{~g}$ ). We first conducted a matched cohort study to identify whether the probiotic had an effect on the prevention of the deterioration of NEC from stage I to II/III. Then, we further explored the risk factors that might play an important role in deterioration of NEC from stage I to II/III by a case-control study. The details of the grouping are shown in Fig. 1.

\section{Statistical analysis}

All data were analyzed by using SPSS 19.0 (SPSS Inc. Chicago, IL), and continuous variables were tested for normality using the Kolmogorov-Smirnov test. Normally distributed continuous data were described as the mean \pm standard deviation $(\mathrm{M} \pm$ S.D.) and were analyzed by $t$ test. Skewed data were described as median (interquartile range, IQR) and were analyzed by MannWhitney $U$ test. Categorical data were analyzed by using the Chi-square test or Fisher exact test. These statistically significant variables were tested again by logistic regression analysis to identify the independent risk factor. Statistical significance was established if $P<0.05$.

\section{Results}

\section{Patient demographics}

In the study, 472 infants with NEC were admitted to the Children's Hospital of Chongqing Medical University. A total of 231 infants met the inclusion criteria for further study, and 241 infants were excluded due to not meeting the criteria (hospitalization less than 3 days in 29 infants,
23 infants using 1-3 days of probiotics, 15 infants with intestinal malformation, 174 infants with stage $\geq \mathrm{II}$ at admission, and 8 infants with incomplete information).

The baseline characteristics of the infants are shown in Table 1. The median gestational age and birth weight of the patients were 37.86 weeks and $2800 \mathrm{~g}$, respectively. Moreover, $39.4 \%(91 / 231)$ of the patients were premature infants. All infants with NEC were fed by formula during hospitalization. Overall, 24.7\% (57/231) of infants progressed to stage $\geq$ II during hospitalization. Before matching, differences in gestational age $(P=0.025)$, birth weight $(P=0.015)$, premature birth $(P=0.044)$, cortical steroid use in pregnancy $(P=0.047)$, anemia $(P=0.003)$ and gastrointestinal decompression $(P=0.048)$ were found between the probiotics group $(n=108)$ and the nonprobiotics group $(n=123)$. After matching, there were 81 pairs of infants who met the matching requirements, and no significant differences in these variables were found between the matched groups $(P>0.05)$.

The complications are shown in Table 2 and Additional file 1: Table S1. Several complications such as anemia (68.8\%), coagulation disorder (59.3\%), hypoproteinemia (51.9\%), sepsis (31.2\%), hypokalemia (32.5\%), thrombocytopenia $(21.2 \%)$ and respiratory failure $(16 \%)$ were found in NEC infants. With the exception of anemia, the main complications had no significant difference between the two groups before or after matching $(P>0.05)$.

The treatment protocols for NEC are shown in Table 3. Gastrointestinal decompression (64.1\%), blood transfusion (23.4\%), and dopamine support (25.5\%) were also used for these NEC infants. Before matching, most treatment protocols had no significant difference between the two groups, with the exception of gastrointestinal decompression $(P=0.048)$. After matching, no difference in therapy was found between the two groups.

\section{The effect of probiotics on the deterioration of NEC between the two groups}

Before matching, we found that the rate of deterioration of NEC from stage I to II/III in the probiotic treatment group was similar to that in the group without probiotic treatment $(23.1 \%$ [25/108] vs $26.0 \%$ [32/123], $P=0.614)$. After matching, the rate of deterioration of NEC between the group with probiotic treatment and the group without probiotic treatment still had no significant difference (21.0\% [17/81] vs $27.2 \%$ [22/81], $P=0.358)$. For those infants who received probiotic treatment, no significant difference in the administration time of probiotics was found between the stage I group $(n=64)$ and the stage $\geq$ II group $(n=17)(9[7-14.75]$ vs $12[6.5-23], P=0.362)$.

\section{The risk factors related to deterioration of NEC}

On the basis of the above findings, an interesting question was put forth regarding which factors may have 
Table 1 The baseline information of NEC infants treated (with/without) probiotics in this study

\begin{tabular}{|c|c|c|c|c|c|c|c|}
\hline \multirow[t]{2}{*}{ Variables } & \multirow[t]{2}{*}{ Total $(n=231)$} & \multicolumn{3}{|l|}{ Before matching } & \multicolumn{3}{|l|}{ After matching $^{a}$} \\
\hline & & With $(n=108)$ & Without $(n=123)$ & $P$ & With $(n=81)$ & Without $(n=81)$ & $P$ \\
\hline Gestational age, IQR, wks & $37.86(34.57-39.71)$ & $37.07(34.04-39.25)$ & $38.43(35.14-39.86)$ & 0.025 & $37.29(34.71-38.86)$ & $38.14(34.86-39.50)$ & 0.128 \\
\hline Premature, \%(n) & $39.4(91)$ & $46.3(50)$ & $33.3(41)$ & 0.044 & $42.0(34)$ & $35.8(29)$ & 0.420 \\
\hline Birth weight, $( \pm S D), g$ & $2800(2000-3305)$ & $2620(1927.5-3180)$ & $3000(2100-3400)$ & 0.015 & $2591.81 \pm 718.45$ & $2705.19 \pm 713.69$ & 0.315 \\
\hline Male, \%(n) & $40.7(94)$ & $48.9(46)$ & $51.1(48)$ & 0.582 & $47.1(32)$ & $52.9(36)$ & 0.524 \\
\hline Vaginal delivery, \%(n) & $42.0(97)$ & $38.0(41)$ & $45.5(56)$ & 0.245 & $39.5(32)$ & $46.9(38)$ & 0.341 \\
\hline The age of onset, IQR, $d$ & $3.44(1.1-11.1)$ & $5.49(1.33-11)$ & $3.14(1-13)$ & 0.355 & $5.57(1.1-10.1)$ & $3.4(1-13.5)$ & 0.988 \\
\hline PROM> $18 h, \%(n)$ & $5.2(12)$ & $2.8(3)$ & $7.3(9)$ & 0.121 & $2.5(2)$ & $6.2(5)$ & 0.440 \\
\hline Amniotic fluid contamination, \%(n) & $13.4(31)$ & $13.9(15)$ & $13.0(16)$ & 0.845 & $16.0(13)$ & $12.3(10)$ & 0.499 \\
\hline Asphyxia, \%(n) & $10.8(25)$ & $9.3(10)$ & $12.2(15)$ & 0.474 & $11.1(9)$ & $13.6(11)$ & 0.633 \\
\hline Infants of diabetic mothers, \%(n) & $2.6(6)$ & $3.7(4)$ & $1.6(2)$ & 0.565 & $3.7(3)$ & $2.5(2)$ & 1.000 \\
\hline $\mathrm{PIH}, \%(n)$ & $5.6(13)$ & $8.3(9)$ & $3.3(4)$ & 0.095 & $8.6(7)$ & $4.9(4)$ & 0.349 \\
\hline$I C P, \%(n)$ & $2.2(5)$ & $2.8(3)$ & $1.6(2)$ & 0.883 & $2.5(2)$ & $1.2(1)$ & 1.000 \\
\hline Antenatal corticosteroids, \%(n) & $3.5(8)$ & $6.5(7)$ & $0.8(1)$ & 0.047 & $6.2(5)$ & $1.2(1)$ & 0.212 \\
\hline
\end{tabular}

$I Q R$ interquartile range, $P R O M$ prolonged rupture of membranes, $P I H$ pregnancy-induced hypertension, $I C P$ intrahepatic cholestasis of pregnancy

${ }^{a}$ We performed 1:1 matching according to close gestational age (difference was $\leq 3$ days) and birth weight (difference was $\leq 400 \mathrm{~g}$ )

contributed to the deterioration from stage I to II/III. We used the matched cases to design a case-control study to find those risk factors. Perinatal factors, complications and treatment therapy were compared between the stage I group $(n=123)$ and the stage $\geq$ II group $(n=$ 39 ), and none of the perinatal factors and baseline characteristics were significantly associated with NEC progression (Table 4 and Additional file 1: Table S2). However, sepsis $(P=0.021)$ after NEC was significantly related to the deterioration of NEC (Table 5). These statistically significant variables were tested again by logistic regression analysis, and sepsis (OR: 2.378, 95\% CI: $1.005-5.628, P=0.049)$ after NEC was identified as the independent risk factor for stage I NEC deteriorating to stage II/III NEC.

\section{Discussion}

There have been many reports that have evaluated probiotic administration for the prevention of NEC. Many previous reports of probiotics found that the use of probiotics was beneficial for the prevention of severe NEC. To our knowledge, data have rarely been specifically

Table 2 The complications or comorbidities of NEC infants treated (with/without) probiotics in this study

\begin{tabular}{|c|c|c|c|c|c|c|c|}
\hline \multirow[t]{2}{*}{ Variables } & \multirow{2}{*}{$\begin{array}{l}\text { Total } \\
(n=231)\end{array}$} & \multicolumn{3}{|c|}{ Before matching } & \multicolumn{3}{|c|}{ After matching $^{a}$} \\
\hline & & With $(n=108)$ & Without $(n=123)$ & $P$ & With $(n=81)$ & Without $(n=81)$ & $P$ \\
\hline NRDS, \%(n) & $7.4(17)$ & $8.3(9)$ & $6.5(8)$ & 0.595 & $7.4(6)$ & $6.2(5)$ & 0.755 \\
\hline Apnea, \%(n) & $6.1(14)$ & $8.3(9)$ & $4.1(5)$ & 0.175 & $6.2(5)$ & $3.7(3)$ & 0.717 \\
\hline Respiratory failure, \%(n) & $16.0(37)$ & $14.8(16)$ & $17.1(21)$ & 0.641 & $13.6(11)$ & $16.0(13)$ & 0.658 \\
\hline Pulmonary hemorrhage, \%(n) & $5.2(12)$ & $4.6(5)$ & $5.7(7)$ & 0.717 & $4.9(4)$ & $7.4(6)$ & 0.514 \\
\hline Sepsis, \%(n) & $31.2(72)$ & $37.0(40)$ & $26.0(32)$ & 0.071 & $39.5(32)$ & $32.1(26)$ & 0.325 \\
\hline Septic shock, \%(n) & $2.6(6)$ & $1.9(2)$ & $3.3(4)$ & 0.552 & $2.5(2)$ & $4.9(4)$ & 0.677 \\
\hline Bacterial meningitis, \%(n) & $4.3(10)$ & $3.7(4)$ & $4.9(6)$ & 0.910 & $3.7(3)$ & $7.4(6)$ & 0.493 \\
\hline Congenital heart disease ${ }^{b}, \%(n)$ & $44.2(102)$ & $45.4(49)$ & $43.1(53)$ & 0.728 & $46.9(38)$ & $46.9(38)$ & 1.000 \\
\hline Cardiac insufficiency, \%(n) & $1.3(3)$ & $1.9(2)$ & $0.8(1)$ & 0.910 & $1.2(1)$ & $1.2(1)$ & 1.000 \\
\hline MODS,\%(n) & $0.4(1)$ & $0(0)$ & $0.8(1)$ & $1.000^{\mathrm{a}}$ & $0(0)$ & $1.2(1)$ & $1.000^{\mathrm{a}}$ \\
\hline Anemia, \%(n) & $68.8(159)$ & $79.6(86)$ & $59.3(73)$ & 0.001 & $76.5(62)$ & $60.5(49)$ & 0.028 \\
\hline Coagulation disorder, \%(n) & $59.3(137)$ & $63.9(69)$ & $55.3(68)$ & 0.184 & $61.7(50)$ & $55.6(45)$ & 0.425 \\
\hline Thrombocytopenia, \%(n) & $21.2(49)$ & $22.2(24)$ & $20.3(25)$ & 0.725 & $23.5(19)$ & $23.5(19)$ & 1.000 \\
\hline
\end{tabular}

NRDS neonatal respiratory distress syndrome, MODS multiple organ dysfunction syndrome

${ }^{a}$ We performed 1:1 matching according to close gestational age (difference was $\leq 3$ days) and birth weight (difference was $\leq 400 \mathrm{~g}$ )

${ }^{b}$ The congenital cardiac lesion: patent ductus arteriosus, ventricular septal defect or atrial septal defect. No special intervention was required in all cases after consultation with cardiologists and cardiac surgeons 
Table 3 The treatment protocols of NEC infants treated (with/without) probiotics in this study

\begin{tabular}{|c|c|c|c|c|c|c|c|}
\hline \multirow[t]{2}{*}{ Variables } & \multirow{2}{*}{$\begin{array}{l}\text { Total } \\
(n=231)\end{array}$} & \multicolumn{3}{|c|}{ Before matching } & \multicolumn{3}{|c|}{ After matching $^{a}$} \\
\hline & & With $(n=108)$ & Without $(n=123)$ & $P$ & With $(n=81)$ & Without $(n=81)$ & $P$ \\
\hline Gastrointestinal decompression, \%(n) & $64.1(148)$ & $57.4(62)$ & $69.9(86)$ & 0.048 & $58.0(47)$ & $67.9(55)$ & 0.193 \\
\hline Duration of gastrointestinal decompression, IQR, $d$ & $4(2-6)$ & $3(2-6)$ & $4(2-6)$ & 0.319 & $3(2-6)$ & $6(2-6)$ & 0.643 \\
\hline Red blood cell transfusion, \%(n) & $23.4(54)$ & $26.9(29)$ & $20.3(25)$ & 0.242 & $22.2(18)$ & $23.5(19)$ & 0.852 \\
\hline Platelet support, \%(n) & $6.5(15)$ & $7.4(8)$ & $5.7(7)$ & 0.597 & $8.6(7)$ & $7.4(6)$ & 0.772 \\
\hline Plasma support, \%(n) & $13.0(30)$ & $12.0(13)$ & $13.8(17)$ & 0.687 & $12.3(10)$ & $13.6(11)$ & 0.815 \\
\hline Intravenous immunoglobulin, \%(n) & $13.4(31)$ & $16.7(18)$ & $10.6(13)$ & 0.175 & $14.8(12)$ & $12.3(10)$ & 0.646 \\
\hline Albumin support, \%(n) & $43.7(101)$ & $41.7(45)$ & $45.5(56)$ & 0.555 & $38.3(31)$ & $44.4(36)$ & 0.425 \\
\hline Dopamine support, \%(n) & $25.5(59)$ & $25.0(27)$ & $26.0(32)$ & 0.860 & $23.5(19)$ & $24.7(20)$ & 0.854 \\
\hline Caffeine support, \%(n) & $9.1(21)$ & $9.3(10)$ & $8.9(11)$ & 0.934 & $8.6(7)$ & $7.4(6)$ & 0.772 \\
\hline
\end{tabular}

${ }^{a}$ We performed 1:1 matching according to close gestational age (difference was $\leq 3$ days) and birth weight (difference was $\leq 400 \mathrm{~g}$ )

focused on whether probiotics prevent the deterioration of NEC from stage I to II/III in infants. In the present study, we found that probiotics could not prevent the deterioration of NEC from stage I to II/III in infants.

Breastfeeding has a protective effect against NEC [13]. Studies have found that human milk is not sterile, and up to 200 different bacterial species have been found in human milk [14]. One study involving the microbial detection of milk samples from healthy women collected at three different time points showed nine bacterial genera were present in all samples but in different concentrations among the subjects [14]. This finding suggests that milk microbes from each mother are optimized for the health of her own infant, and breast milk of healthy women is a source of commensal bacteria in the infant gut [15]. Therefore, the administration of large-scale industrially produced probiotics regardless of the NEC infants' individual characteristics of intestinal microbes may not reduce the deterioration of NEC.

There are currently no unified standards for access schemes detailing routine use in the prevention of NEC. Probiotic type, dosage and administration timing may affect the influence of probiotics on the incidence of
NEC, and controversial findings of the influence of probiotics on the incidence of NEC have been published [16-18] One guideline suggested that a daily dose of $3 \times 10^{9} \mathrm{cfu} /$ day may be appropriate for neonates of less than 32 weeks gestation [16]. Evidence indicates that to be functional, probiotics have to be viable and at sufficient dosage levels, typically $10^{6}$ to $10^{7} \mathrm{cfu} / \mathrm{g}$ of product, and many probiotic products have the same dose of bacteria [16]. It is not clear whether $10^{6}$ to $10^{7}(\mathrm{cfu}) / \mathrm{g}$ of product is effective in preventing the deterioration of NEC from stage I to II/III. Furthermore, given that the dose of $10^{6} \mathrm{cfu}$ used in the present study was much lower than other studies $\left(10^{7} \sim 10^{10} \mathrm{cfu}\right)[17,18]$, the conclusion should be treated with caution.

Early initiation of enteral feeding after NEC may have a beneficial effect on the recovery of the intestinal mucosa [19]. In contrast, late initiation of enteral feeding may lead to mucosal villous atrophy $[19,20]$. There is a lack of consensus among surgeons and neonatologists regarding the optimal feeding strategy after an NEC diagnosis to prevent its recurrence. Most textbooks suggest bowel rest for 7 to 10 days, but there is a lack of clinical evidence to support this recommendation [21].

Table 4 The treatment protocols between stage I and $\geq \|$ NEC infants after matching

\begin{tabular}{llll}
\hline Variables & Stage I $(n=123)$ & $\geq$ Stage II $(n=39)$ & $P$ \\
\hline Gastrointestinal decompression, \%(n) & $57.7(71)$ & $79.5(31)$ & $3(2-6)$ \\
Duration of gastrointestinal decompression, d & $4(2-6)$ & $0(0)$ & 0.014 \\
Blood exchange transfusion, \%(n) & $0.8(1)$ & $20.5(8)$ & 1.000 \\
Red blood cell support, \%(n) & $23.6(29)$ & $10.3(4)$ & 0.691 \\
Platelet support, \%(n) & $13.8(17)$ & $12.8(5)$ & 0.564 \\
Plasma or cryoprecipitate support, \%(n) & $13.8(17)$ & $38.5(15)$ & 0.874 \\
Intravenous immunoglobulin, \%(n) & $42.3(52)$ & $23.1(9)$ & 0.673 \\
Albumin support, \%(n) & $24.4(30)$ & $10.3(4)$ & 0.867 \\
Dopamine support, \%(n) & $7.3(9)$ & 0.802
\end{tabular}

We performed 1:1 matching according to close gestation age (difference was $\leq 3$ days) and birth weight (difference was $\leq 400 \mathrm{~g}$ ) 
Table 5 Comparison of complications between infants with NEC stage I and those with $\geq||$ after matching

\begin{tabular}{llll}
\hline Variables & Stage I $(n=123)$ & $\geq$ Stage II $(n=39)$ & $P$ \\
\hline Neonatal respiratory syndrome, \%(n) & $8.1(10)$ & $2.6(1)$ & 0.402 \\
Apnea, \%(n) & $4.1(5)$ & $7.7(3)$ & 0.626 \\
Respiratory failure, \%(n) & $15.4(19)$ & $12.8(5)$ & 0.687 \\
Pulmonary hemorrhage, \%(n) & $7.3(9)$ & $2.6(1)$ & 0.488 \\
Sepsis, \%(n) & $30.9(38)$ & $51.3(20)$ & 0.021 \\
Septic shock, \%(n) & $4.1(5)$ & $2.6(1)$ & 1.000 \\
Bacterial meningitis, \%(n) & $5.7(7)$ & $5.1(2)$ & 1.000 \\
Congenital heart disease, \%(n) & $46.3(57)$ & $48.7(19)$ & 0.796 \\
Anemia, \%(n) & $69.9(86)$ & $64.1(25)$ & 0.496 \\
Coagulation disorder, \%(n) & $59.3(73)$ & $56.4(22)$ & 0.745 \\
Thrombocytopenia, \%(n) & $25.2(31)$ & $17.9(7)$ & 0.352 \\
Cold injury syndrome, \%(n) & $3.3(4)$ & $5.1(2)$ & 0.957 \\
Hypoproteinemia, \%(n) & $52.0(64)$ & $46.2(18)$ & 0.522 \\
\hline
\end{tabular}

We performed 1:1 matching according to close gestational age (difference was $\leq 3$ days) and birth weight (difference was $\leq 400 \mathrm{~g}$ )

Initiating early enteral feeding within 5 days of NEC diagnosis (Bell stage II or above) is not associated with adverse outcomes, including NEC recurrence [22]. There was also no guideline regarding the initiation of feeding for infants with NEC Bell stage I.

There are some limitations in this study, including the errors and biases inherent to the nature of a retrospective study. In the present study, we performed 1:1 matching by using similar gestational age and birth weight, and it led to a loss of approximately $30 \%$ of sample capacity. Therefore, the overall sample capacity of the study was relatively small.

\section{Conclusions}

In summary, we found that probiotics might not prevent the deterioration of NEC, but this conclusion should be treated with caution.

\section{Additional file}

Additional file 1: Table S1. The complications of NEC infants treated (with/without) probiotics in this study. Table S2. Comparison of baseline information between infants with NEC stage I and those with $\geq I$. (DOCX $20 \mathrm{~kb}$ )

\section{Acknowledgements}

We thank Dr. Jialin Yu for great help to analyze the data.

\section{Funding}

This work was supported by the National Natural Science Foundation of China (Grant No. 81601323), the Scientific Research Foundation of The science and Technology Commission of Chongqing (Grant No.cstc2015jcyjA10089, cstc2018jscx-msybx0027) and Chongqing Municipal Administration of Human Resources and Social Security (Grant No.Cx2017107),

\section{Availability of data and materials}

The datasets used and/or analyzed during the current study are available from the corresponding author on reasonable request.

\section{Authors' contributions}

This study was conceptualized by ZLW and LL, while L-QL designed it. $L L$ collected the data; X-YH, LG, Q-YL, YA, Y-JJ, SC, X-QW, YH analyzed and interpreted the data. Z-LW and LL wrote this manuscript. All authors read and approved the final manuscript

\section{Ethics approval and consent to participate}

This study was carried out in accordance with the Declaration of Helsinki and was approved by the Ethics Committee of the Children's Hospital of Chongqing Medical University. The study was a retrospective matched cohort study. Considering the anonymized nature of the data and scientific purpose of this study, the requirements for informed consent were waived by the Ethics Committee of Children's Hospital of Chongqing Medical University.

Consent for publication

Not applicable.

Competing interests

The authors declare that they have no competing interests.

\section{Publisher's Note}

Springer Nature remains neutral with regard to jurisdictional claims in published maps and institutional affiliations.

\section{Author details}

'Department of Neonatal Diagnosis and Treatment Center, Children's Hospital of Chongqing Medical University, No 136, Zhong shan 2 Road, Yuzhong district, Chongqing 400014, People's Republic of China. ${ }^{2}$ Key Laboratory of Pediatrics in Chongqing, Chongqing 400014, People's Republic of China. ${ }^{3}$ Chongqing International Science and Technology Cooperation Center for Child Development and Disorders, Chongqing 400014, People's Republic of China.

Received: 7 February 2019 Accepted: 29 April 2019

Published online: 08 June 2019

\section{References}

1. Neu J. Necrotizing enterocolitis: the mystery goes on. Neonatology. 2014; 106(4):289-95

2. Neu J. Necrotizing enterocolitis. World Rev Nutr Diet. 2014;110:253-63.

3. Suarez Rodriguez M, Solis Sanchez G. Use of probiotics in the prevention of necrotizing enterocolitis in premature newborns. Nutr Hosp. 2015;31(Suppl 1):68-71. 
4. Costeloe K, Bowler U, Brocklehurst P, Hardy P, Heal P, Juszczak E, King A, Panton N, Stacey F, Whiley A, et al. A randomised controlled trial of the probiotic Bifidobacterium breve BBG-001 in preterm babies to prevent sepsis, necrotising enterocolitis and death: the probiotics in preterm infantS (PiPS) trial. Health Technol Assess. 2016;20(66):1-194.

5. Chowdhury T, Ali MM, Hossain MM, Singh J, Yousuf AN, Yasmin F, Chowdhury FR. Efficacy of probiotics versus placebo in the prevention of necrotizing enterocolitis in preterm very low birth weight infants: a double-blind randomized controlled trial. J Coll Physicians Surg Pak. 2016;26(9):770-4.

6. Sawh SC, Deshpande S, Jansen S, Reynaert CJ, Jones PM. Prevention of necrotizing enterocolitis with probiotics: a systematic review and metaanalysis. PeerJ. 2016;4:e2429.

7. Thomas JP, Raine T, Reddy S, Belteki G. Probiotics for the prevention of necrotising enterocolitis in very low-birth-weight infants: a meta-analysis and systematic review. Acta Paediatr. 2017:106(11):1729-41.

8. Hickey L, Jacobs SE, Garland SM. Probiotics in neonatology. J Paediatr Child Health. 2012;48(9):777-83.

9. Ostlie DJ, Spilde TL, Peter SDS, Sexton N, Miller KA, Sharp RJ, Gittes GK, Snyder CL. Necrotizing enterocolitis in full-term infants. J Pediatr Surg. 2003; 38(7):1039-42

10. Miner CA, Fullmer S, Eggett DL, Christensen RD. Factors affecting the severity of necrotizing enterocolitis. J Matern Fetal Neonatal Med. 2013; 26(17):1715-9.

11. Bell MJ, Ternberg JL, Feigin RD, Keating JP, Marshall $R_{1}$,, Barton $L_{\text {, ., }}$ Brotherton T, . Neonatal necrotizing enterocolitis. Therapeutic decisions based upon clinical staging. Ann Surg 1978, 187(1):1.

12. Walsh MC, Kliegman RM. Necrotizing enterocolitis: treatment based on staging criteria. Pediatr Clin N Am. 1986;33(1):179-201.

13. Miller J, Tonkin E, Damarell RA, Mcphee AJ, Suganuma M, Suganuma H, Middleton PF, Makrides M, Collins CT. A systematic review and metaanalysis of human Milk feeding and morbidity in very low birth weight infants. Nutrients. 2018;10(6):707.

14. Hunt KM, Foster JA, Forney LJ, Schutte UM, Beck DL, Abdo Z, Fox LK, Williams JE, McGuire MK, McGuire MA. Characterization of the diversity and temporal stability of bacterial communities in human milk. PLoS One. 2011; 6(6):e21313.

15. Martín R, Heilig HGHJ, Zoetendal EG, Jiménez E, Fernández L, Smidt H, Rodríguez JM. Cultivation-independent assessment of the bacterial diversity of breast milk among healthy women. Res Microbiol. 2007;158(1):31-7.

16. Deshpande GC, Rao SC, Keil AD, Patole SK. Evidence-based guidelines for use of probiotics in preterm neonates. BMC Med. 2011;9(1):92.

17. Costeloe K, Hardy P, Juszczak E, Wilks M, Millar MR. Bifidobacterium breve BBG-001 in very preterm infants: a randomised controlled phase 3 trial. Lancet. 2016;387(10019):649-60.

18. Escribano E, Zozaya C, Madero R, Sánchez L, Van GJ, Rodríguez JM, de Pipaon MS. Increased incidence of necrotizing enterocolitis associated with routine administration of Infloran ${ }^{T M}$ in extremely preterm infants. Benefic Microbes. 2018:9(5):1.

19. Kliegman RM, Walker WA, Yolken RH. Necrotizing enterocolitis: research agenda for a disease of unknown etiology and pathogenesis. Pediatr Res. 1993;34(6):701.

20. Bertolo RF, Chen CZ, Pencharz PB, Ball RO. Intestinal atrophy has a greater impact on nitrogen metabolism than liver by-pass in piglets fed identical diets via gastric, central venous or portal venous routes. J Nutr. 1999;129(5):1045.

21. Bohnhorst B, Müller S, Dördelmann M, Peter CS, Petersen C, Poets CF. Early feeding after necrotizing enterocolitis in preterm infants. J Pediatr. 2003; 143(4):484-7.

22. Brotschi B, Baenziger O, Frey B, Bucher HU, Ersch J. Early enteral feeding in conservatively managed stage II necrotizing enterocolitis is associated with a reduced risk of catheter-related sepsis. J Perinat Med. 2009;37(6):701-5.

\section{Ready to submit your research? Choose BMC and benefit from}

- fast, convenient online submission

- thorough peer review by experienced researchers in your field

- rapid publication on acceptance

- support for research data, including large and complex data types

- gold Open Access which fosters wider collaboration and increased citations

- maximum visibility for your research: over $100 \mathrm{M}$ website views per year

At $\mathrm{BMC}$, research is always in progress.

Learn more biomedcentral.com/submissions 